\title{
Flow Electrochemical Cyclizations via Amidyl Radicals: Easy Access to Cyclic Ureas
}

\author{
Nisar Ahmed*a,b (D) \\ Aggeliki Vgenopoulou ${ }^{a}$ \\ a School of Chemistry, Cardiff University, Park Place, Cardiff, \\ CF10 3AT, UK \\ AhmedN14@cardiff.ac.uk

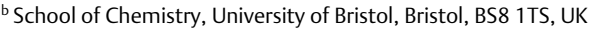

Received: 11.01.2019

Accepted after revision: 03.03.2019

Published online: 27.03 .2019

DOI: 10.1055/s-0037-1611772; Art ID: so-2019-d0002-I

License terms: (C)

Abstract Flow chemistry has advantages over batch processes and can achieve the synthesis of substances in high yield under safe working conditions. The combination of electrochemistry and flow microreactor technology has made chemical transformations possible without the use of oxidants or catalysts. Herein, we report flow electrosynthesis of cyclic ureas via oxyamination of $\mathrm{N}$-allylic ureas. We have found that continuous flow is able to outperform its batch counterpart, producing cyclic ureas in excellent yields.

Key words alkenes functionalization, microreactor technology, flow electrosynthesis, oxyamination, cyclic ureas

Flow electrochemistry has begun to add to the ever increasing arsenal of techniques available to the synthetic chemist. ${ }^{1}$ Flow electrosynthesis performed in microreactors offers a number of benefits, allowing reactions to be performed in a more convenient and safer manner, ${ }^{2}$ and even allow electrochemical reactions to take place without a supporting electrolyte due to a very short interelectrode distance $^{3}$ that results in the two diffusion layers of the electrodes becoming 'coupled', allowing ions to be electrogenerated and play the role of the electrolyte. Continuous-flow electrochemistry has the potential to act as a new enabling technology to replace some aspects of conventional batch electrochemical processes. ${ }^{4}$

Electrochemical functionalization of double bonds is an important and environmentally benign method for introducing complexity into molecules. ${ }^{5}$ While batch electrochemical protocols have been available for some time, flow electrochemistry methods have only recently appeared as useful additions to the synthetic portfolio. ${ }^{6}$ We have contributed to this development by reporting an electrochemi-

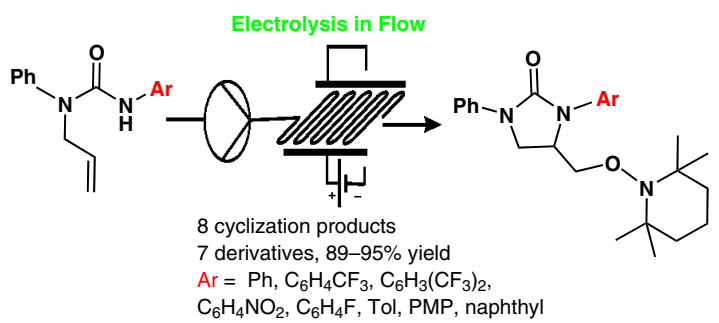

cal microreactor with a very small inter-electrode gap, which is useful for the synthesis of thiazolidines (Scheme 1, Eq. (1)). ${ }^{7}$

Recently, we have investigated urea derivatives that allow the generation of $\mathrm{N}$-centered radicals under electrochemical reaction conditions in an undivided cell. These nitrogen radicals react with alkenes and the resulting carbon radicals can be trapped with 2,2,6,6-tetramethylpiperidine1-oxyl (TEMPO) resulting in the addition of a nitrogen and an oxygen atom to the double bond. In this way, we have synthesized various cyclic ureas derivatives in a batch electrochemical process (Scheme 1, Eq. (2)). ${ }^{8}$ However, to facilitate access to these cyclic ureas, we decided to apply flow conditions, by replacing the inorganic base $\mathrm{Na}_{2} \mathrm{CO}_{3}$ with the organic base Triton $\mathrm{B}$. Herein, we report a method for the

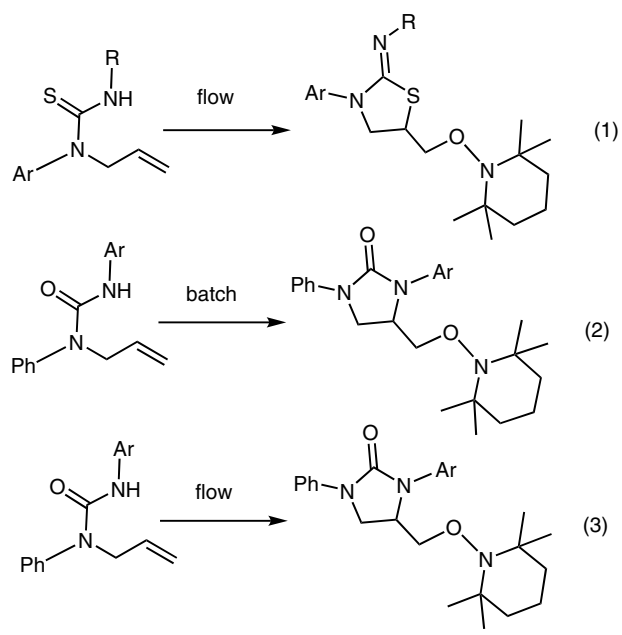

Scheme 1 Electrochemical 1,2-difunctionalization of double bonds. 
electrochemical cyclization of $\mathrm{N}$-allyl substituted ureas in combination with TEMPO, using an undivided electrochemical flow cell, as shown in Scheme 1, Eq. (3).

The allyl-substituted urea derivatives $\mathbf{3}$ as substrates for such electrochemical cyclizations were obtained in a straightforward route from mono-allyl anilines $\mathbf{1}$ and isocyanates $\mathbf{2}$, as has been described earlier. ${ }^{8}$

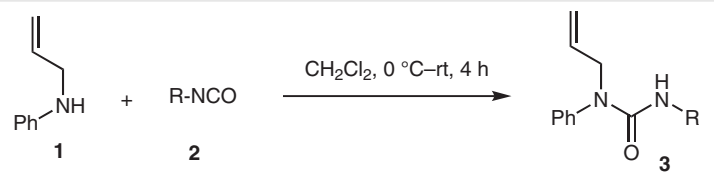

Scheme 2 Synthesis of urea derivatives 3

The flow reaction was performed in our recently developed flow electrochemistry system ${ }^{7}$ and an ion electrochemical reactor (IER). ${ }^{9}$ It was found that the flow rates could be varied and, with flow rates up to $0.2 \mathrm{~mL} \mathrm{~min}^{-1}$, full conversion at room temperature was observed. A schematic setup of the flow system is shown in Scheme 3.

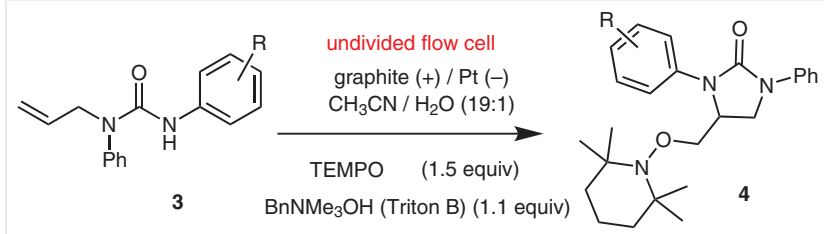

Scheme 3 Flow electrochemical synthesis of cyclic ureas

The substrates 3 are dissolved in a 19:1 mixture of acetonitrile and water together with TEMPO (1.5 equiv) and benzyltrimethylammonium hydroxide (1.1 equiv) and electrolysed using a graphite anode and platinum cathode with $3 \mathrm{~F}$ in a flow electrochemical microreactor. ${ }^{7}$

$N$-Allyl ureas $\mathbf{3 a - h}$, with different aryl substituents on the monosubstituted urea nitrogen, were cyclized under optimized reaction conditions to the cyclic ureas 4 . The cyclic urea products could be isolated in excellent yields (89$95 \%$, Figure 1). The reaction proceeded smoothly with a range of substituents on the aryl moiety although, in the case of naphthyl substituted urea substrate $\mathbf{3 h}$, the reaction gave low yield (37\%).

The proposed mechanism for the amination of the $\mathrm{N}$-allyl urea derivatives 3 is shown in Scheme 4. A radical generated at the urea amide nitrogen atom subsequently undergoes cyclization and reacts with TEMPO to give the cyclic urea products 4. The electrolysis process originates from anodic oxidation of TEMPO to the oxoammonium ion and cathodic reduction of water $\left(\mathrm{H}_{2} \mathrm{O}\right)$ to hydroxide $\left(\mathrm{OH}^{-}\right)$and $\mathrm{H}_{2}$. Then deprotonation of the urea by electrogenerated hydroxide, or with Triton B, leads to an amidyl nitrogen anion. Single-electron transfer between the anionic urea and the
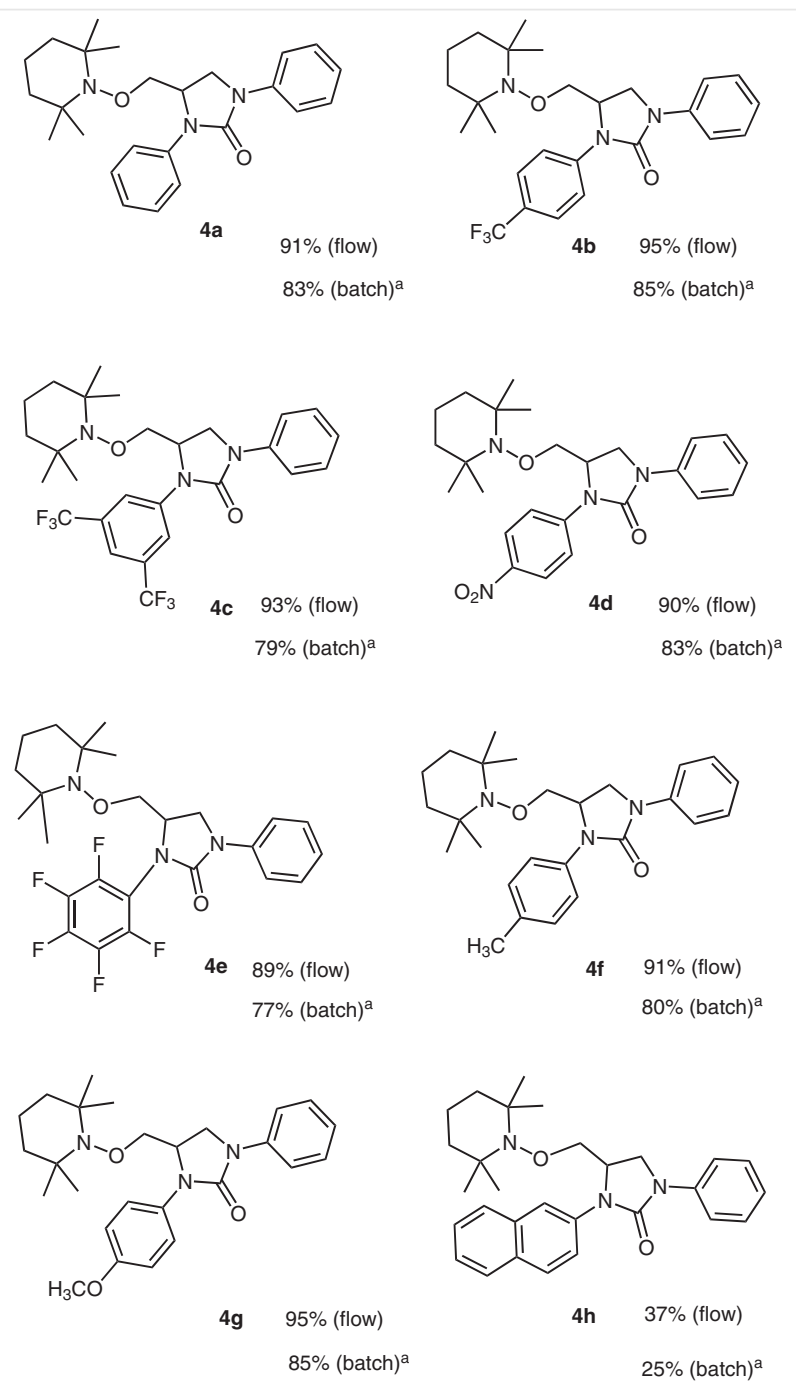

Figure 1 Substrate scope for the electrochemical cyclization of $\mathrm{N}$-allyl

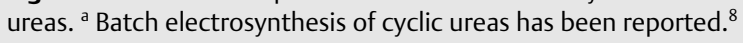

oxoammonium ion affords the amidyl nitrogen radical and regenerates the TEMPO radical molecule. The amidyl nitrogen radical intermediate can then cyclise onto the cyclic urea group to give another radical at the terminal carbon that is trapped by the TEMPO radical molecule to form the difunctionalized oxyamination product of the cyclic urea.

In conclusion, we have demonstrated that cyclic ureas can be synthesized in an electrochemical reaction. The use of an electrochemical flow reactor enables the easy synthesis of compounds in a straightforward way with high yields at room temperature as compared to batch electrosynthesis. ${ }^{8}$ Compared with previous procedures, ${ }^{10-13}$ this inexpensive, metal-free and environmentally friendly method ${ }^{14}$ provides high yields under mild reaction conditions. 


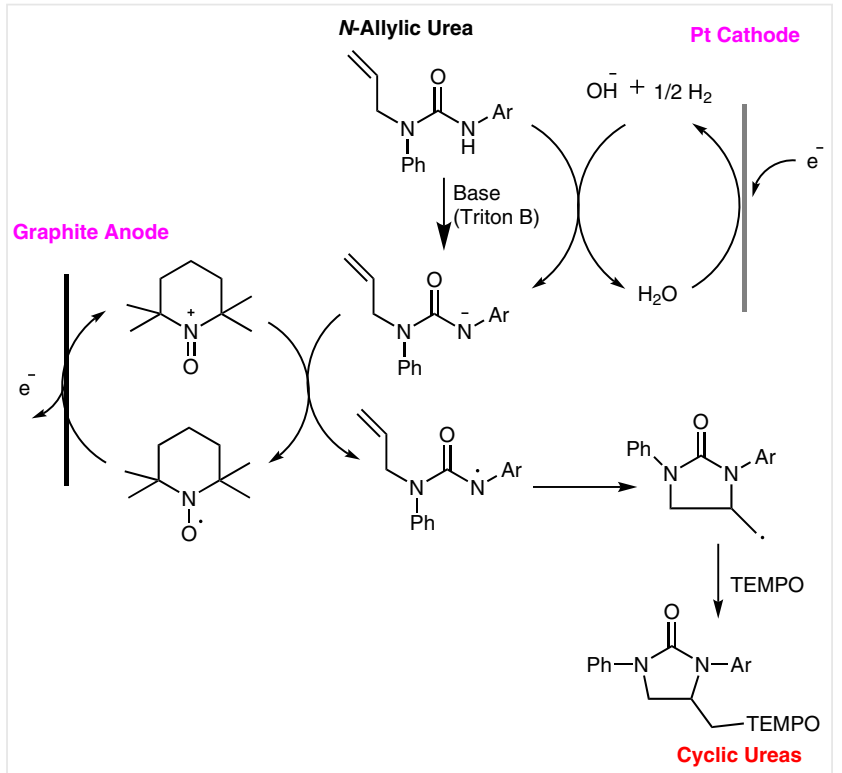

Scheme 4 Proposed mechanism for the synthesis of cyclic ureas end up with alkene difunctionalization of oxoamination

\section{Funding Information}

Support from the EU Horizon 2020 project (Grant No 663830) and the School of Chemistry, Cardiff University, UK, is gratefully acknowledged.

\section{Acknowledgment}

We thank Saira Khatoon, Nasser Amri, and Dominic Sear for technical assistance.

\section{Supporting Information}

Supporting information for this article is available online at https://doi.org/10.1055/s-0037-1611772.

\section{References and Notes}

(1) (a) Suga, S.; Okajima, M.; Fujiwara, K.; Yoshida, J. J. Am. Chem. Soc. 2001, 123, 7941. (b) Kuhn, S.; Noël, T.; Gu, L.; Heider, P. L.; Jensen, K. F. Lab Chip 2011, 11, 2488. (c) Gütz, C.; Stenglein, A.;
Waldvogel, S. R. Org. Process Res. Dev. 2017, 21, 771. (d) Green, R. A.; Brown, R. C. D.; Pletcher, D.; Harji, B. Org. Process Res. Dev. 2015, 19, 1424.

(2) Folgueiras-Amador, A. A.; Philipps, K.; Guilbaud, S.; Poelakker, J.; Wirth, T. Angew. Chem. Int. Ed. 2017, 56, 15446; Angew. Chem. 2017, 129, 15648.

(3) Folgueiras-Amador, A. A.; Qian, X.-Y.; Xu, H.-C.; Wirth, T. Chem. Eur. J. 2018, 24, 487.

(4) Folgueiras-Amador, A.; Wirth, T. J. Flow Chem. 2017, 7, 94.

(5) (a) Martins, G. M.; Shirinfar, B.; Hardwick, T.; Ahmed, N. ChemElectroChem 2019, 6, 1300. (b) Ahmed, N.; Khatoon, S.; Shirinfar, B. ChemElectroChem 2018, 5, 1245.

(6) (a) Atobe, M.; Tateno, H.; Matsumura, Y. Chem. Rev. 2018, 118, 4541. (b) Hardwick, T.; Ahmed, N. RSC Adv. 2018, 8, 22233.

(7) Islam, M.; Kariuki, B. M.; Shafiq, Z.; Wirth, T.; Ahmed, N. Eur. J. Org. Chem. 2019, 1371.

(8) Ahmed, N.; Khatoon, S. ChemistryOpen 2018, 7, 576.

(9) https://www.vapourtec.com/products/flow-reactors/ionelectrochemical-reactor-videos/

(10) (a) Muñiz, K.; Hövelmann, C. H.; Streuff, J. J. Am. Chem. Soc. 2008, 130, 763. (b) Streuff, J.; Hövelmann, C. H.; Nieger, M.; Muñiz, K. J. J. Am. Chem. Soc. 2005, 127, 14586.

(11) (a) Muñiz, K.; Iglesias, A.; Fang, Y. Chem. Commun. 2009, 5591. (b) Li, H.; Widenhoefer, R. A. Tetrahedron 2010, 66, 4827.

(12) (a) Cochran, B. M.; Michael, F. E. Org. Lett. 2008, 10, 5039. (b) Farid, U.; Wirth, T. Angew. Chem. Int. Ed. 2012, 51, 3462.

(13) Rao, W.-H.; Yin, X.-S.; Shi, B.-F. Org. Lett. 2015, 17, 3758.

(14) General Procedure for Flow Electrolysis

The $N$-allylic urea $(0.20 \mathrm{mmol})$ was dissolved in a mixture of acetonitrile/water (19:1, $8.30 \mathrm{~mL})$, then TEMPO (0.30 mmol, 1.5 equiv) and benzyltrimethylammonium hydroxide solution (Triton B, 40\% solution in water, $0.21 \mathrm{mmol}, 1.1$ equiv) were added to the solution, and the mixture was electrolyzed in the electrochemical reactor, fitted with a graphite anode and a platinum cathode and separated by a FEP (fluorinated ethylene propylene) film spacer of 500 ( $\mathrm{m}(0.40 \mathrm{~mL}$ inner volume; $3 \mathrm{~F}, 1-3$ $\mathrm{V})$, by using a syringe pump $\left(0.1 \mathrm{~mL} \mathrm{~min}{ }^{-1}\right)$. After attaining steady flow, the solution $(8.0 \mathrm{~mL})$ was collected in a vial after 100 min. The resulting reaction mixture was quenched with saturated aqueous $\mathrm{NH}_{4} \mathrm{Cl}(5 \mathrm{~mL})$, concentrated in vacuo, diluted with water $(25 \mathrm{~mL})$, and extracted with ethyl acetate $(25 \mathrm{~mL})$. The aqueous phase was extracted with ethyl acetate $(3(20 \mathrm{~mL})$, and the extracts were washed with brine. The combined organic layers were dried over anhydrous $\mathrm{MgSO}_{4}$, filtered, and the filtrate concentrated in vacuo. The residue was purified by column chromatography, eluting with hexane/ethyl acetate, 9:1, giving the pure cyclic urea. Spectroscopic data (NMR, MASS) were in agreement with reported data given in reference 8 . 